\title{
Immunocytochemical study of canine lymphomas and its correlation with exposure to tobacco smoke
}

\author{
K. C. Pinello ${ }^{1}$, M. Santos ${ }^{2}$, L. Leite-Martins ${ }^{1}$, J. Niza-Ribeiro ${ }^{3,4}$ and A. J. de Matos $^{1,5}$
}

1. Department of Veterinary Clinics, Institute of Biomedical Sciences Abel Salazar, University of Porto, Porto, Portugal; 2. Department of Microscopy, Institute of Biomedical Sciences Abel Salazar, University of Porto, Porto, Portugal; 3. Department of Population Studies, Institute of Biomedical Sciences Abel Salazar, University of Porto, Porto, Portugal; 4. EPI Unit, Institute of Public Health, ISPUP - University of Porto, Porto, Portugal; 5. Animal Science and Study Centre, Food and Agrarian Sciences and Technologies Institute, University of Porto, Porto, Portugal.

Corresponding author: K. C. Pinello, e-mail: katiapinello@gmail.com

Co-authors: MS: mssantos@icbas.up.pt, LL: Imartins@icbas.up.pt,.JN: nizaribeiro@gmail.com, AJM: ajmatos@icbas.up.pt

Received: 14-07-2017, Accepted: 04-10-2017, Published online: 08-11-2017

doi: 10.14202/vetworld.2017.1307-1313 How to cite this article: Pinello KC, Santos M, Leite-Martins L, Niza-Ribeiro J, de Matos AJ (2017) Immunocytochemical study of canine lymphomas and its correlation with exposure to tobacco smoke, Veterinary World, 10(11): 1307-1313.

\begin{abstract}
Aim: Canine lymphoma is one of the most common canine neoplasms, but little is known regarding the effects of exposure to tobacco smoke on their biologic behavior. As cytology is the most frequent diagnostic method of canine lymphoma, the aims of this study were to perform an immunocytochemical study of canine lymphomas, including subtyping and cell proliferation analysis, and to establish their correlation with tobacco smoke exposure.
\end{abstract}

Materials and Methods: A total of 23 dogs diagnosed with lymphoma were subjected to careful fine-needle biopsies of enlarged lymph nodes. The smears were air-dried, fixed with cold acetone, and immunocytochemically stained using CD3, PAX5, and Ki-67. Owners were requested to complete an epidemiologic questionnaire.

Results: According to the updated Kiel classification, 65\% were B-cell lymphomas - three low grade (LG) and 12 high grade $(\mathrm{HG})$ and $35 \%$ were T-cell - two LG and six HG. Thirteen tumors presented high Ki67 indexes $(>40 \%)(11 \mathrm{HG}$ and 2 LG), two revealed moderate ones (20-40\%) (1 HG and $1 \mathrm{LG})$, and three had low indexes $(\leq 20 \%)(1 \mathrm{HG}$ and $2 \mathrm{LG})$. Both a significant positive correlation and a significant linear-by-linear association $(\mathrm{p}=0.018)$ were observed between high Ki67 indexes and smoking owners $(r=0.753, p=0.002)$ as well as with the number of smokers in the household ( $\mathrm{r}=0.641$, $\mathrm{p}=0.001)$. Moreover, the mean percentage of Ki67 cells from the group of "smoker owners" was statically higher $(\mathrm{p}=0.011)$ than that from the "non-smoker owners."

Conclusion: The results suggest that cytological diagnosis of canine lymphomas benefits from being complemented with immunocytochemical studies that include subtyping and assessment of proliferative activity, both contributing for the prognosis and therapeutic planning. Furthermore, exposure to tobacco smoke seems to be related to the biological behavior of canine lymphomas.

Keywords: canine lymphoma, immunocytochemistry, proliferation, tobacco smoke.

\section{Introduction}

Lymphomas are a wide and motley group of neoplasms which includes several subtypes with distinct clinical and epidemiological characteristics [1]. They represent one of the most common neoplasms of the dog, comprising approximately $7-24 \%$ of all neoplasms in this species [2]. The increasing frequency of canine lymphomas $[2,3]$ mimics a trend in human oncology in which non-Hodgkin's lymphoma (NHL) represents $5 \%$ of all new cancer cases, currently being one of the top five leading cancer-related deaths [4]. Dogs and humans are close companions and thus subjected to similar indoor and outdoor environmental

Copyright: Pinello, et al. Open Access. This article is distributed under the terms of the Creative Commons Attribution 4.0 International License (http://creativecommons.org/licenses/by/4.0/), which permits unrestricted use, distribution, and reproduction in any medium, provided you give appropriate credit to the original author(s) and the source, provide a link to the Creative Commons license, and indicate if changes were made. The Creative Commons Public Domain Dedication waiver (http://creativecommons.org/ publicdomain/zero/1.0/) applies to the data made available in this article, unless otherwise stated. influences. Therefore, epidemiological studies using dogs as sentinels provide an opportunity to assess the effects of environmental factors on the biologic behavior of cancer $[5,6]$.

Contrary to human medicine, and often due to financial constraints, cytology plays a key role in the diagnosis of canine lymphoma [3]. The cytological analysis is a suitable, easy, and inexpensive diagnostic method, which is in agreement with the histological classification of most subtypes [3]. According to our experience, more than $70 \%$ of lymphoma diagnoses in dogs are achieved through cytology (unpublished data). A recent publication [7] calculated that $90 \%$ of all canine lymphoma diagnoses were obtained using cytology. Although immunocytochemistry (ICC) [8] was studied in the past decades, it has not been routinely included in the diagnostic approach of canine lymphomas $[9,10]$.

The updated Kiel classification adapted to the canine species [11] is the most frequently used classification scheme for the cytological diagnosis 
of canine lymphomas [9,11-13]. Lymphomas are essentially classified on the basis of cell morphology and immunological characteristics and subtyped according to the fundamental distinction between phenotypes (B or $\mathrm{T}$ ) and malignancy grades (low or high) [13]. Such evaluations allow for a $90 \%$ accurate characterization $[5,10,14]$. As in human medicine, the classification of lymphomas is an important prognostic tool $[12,15,16]$ since, if left untreated, high-grade (HG) lymphomas have significantly higher mortality rates than low-grade (LG) ones [17]. Yet, the former responds better to aggressive chemotherapeutic protocols, sometimes even achieving complete remissions [18]. There are, however, variations in survival rates within similar subtypes and grades, suggesting that an individual accurate prognosis may benefit from additional evaluations, such as the analysis of proliferative activity at the time of diagnosis $[9,18]$.

Epidemiological studies of companion animals have been increasing, defining the dog as a sentinel [19] of potential risk factors for human health, mainly due to shared environments, shorter disease latency, and spontaneous diseases as lymphomas [6,20-23]. Several environmental and lifestyle factors were associated with human NHL [24], and these seem to influence both the overall and subtypes incidences $[1,25]$. One of these factors is the exposure to cigarette smoking, which represents a risk factor primarily for follicular lymphomas in human patients [26]. Some studies have shown different risk factors for the development of canine lymphomas such as breed [27], sex and hormonal exposure [28], Bartonella infection [29], oxidative stress [30], household chemicals [6,31], herbicides [32], magnetic fields [33], and air pollution [5,19-21,34]. It is noteworthy, though, that no environmental factors were related to the biological behavior of spontaneous canine lymphomas.

Epidemiological data evidenced a correlation between tobacco smoking and numerous human cancers [35]. Furthermore, new insights emerged regarding second-hand smoking, also named "environmental tobacco smoke" (ETS), "passive smoking," or "involuntary smoking" [36], as well as third-hand smoking (THS) [37]. ETS consists on inhaling both the smoke exhaled by smokers and the sidestream smoke produced by the burning cigarette that contains the same carcinogenic compounds inhaled during active smoking [38]. In addition, when someone smokes, several nicotine-like contaminants are exhaled and settle down on various household surfaces and objects (carpets, table tops, utensils, and furniture), remaining there for weeks or months [37]. These are later reemitted in a gas phase, reacting with oxidants and other environmental compounds, a phenomenon that characterizes the THS [37]. Companion animals are undoubtedly second-hand smokers [39], and most certainly, third-hand smokers when sharing the household with smoking owners. As "active sniffers," dogs are even more exposed to a wide range of potential chemical carcinogens that easily surpass the exposure to which human adults or children are subjected.

Although human studies suggested a positive association between tobacco exposure and the risk of follicular NHL [38], veterinary studies on the effects of tobacco smoke on lymphomas are inexistent.

The aim of this study was to assess the role of the immunocytochemical evaluation of canine lymphomas in the improvement of current routine diagnosis. Furthermore, another goal was to identify associations between exposure to several environmental factors, including exposure to tobacco smoke, lymphoma subtypes, and their biological behavior.

\section{Materials and Methods}

\section{Ethical approval}

The study was approved by the Bioethics Committee of the Institute of Biomedical Sciences Abel Salazar of the University of Porto (ORBEA-ICBAS-UP).

A prospective series of 23 dogs with a cytological diagnosis of lymphoma was considered. From each dog, lymph node cytological specimens were collected for diagnostic purposes. Owners were informed about the aims and methods of the study and signed an informed consent form. Dogs that had received previous chemotherapy were excluded from the study.

\section{Immunocytochemistry}

Fine-needle aspiration biopsies, or just fine-needle biopsies (FNB), were obtained using a 21-gauge needle without aspiration. The material inside the needle was immediately smeared using a $10 \mathrm{ml}$ disposable plastic syringe and air-dried. A minimum of six smears per enlarged lymph node were produced. Submandibular lymph nodes were avoided, whenever possible because their drainage of the oral cavity consistently yields marked hyperplastic features [40]. For diagnostic purposes, a minimum of two smears were stained with Hemacolor (Merck, Darmstadt, Germany). Lymphoma was diagnosed when the normal heterogeneous population of lymphocytes was replaced by predominantly immature and/or monomorphic lymphoid cells $[41,42]$.

For the immunocytochemical assays, smears were dried, fixed in cold acetone for $2 \mathrm{~min}$, stored at $2-6^{\circ} \mathrm{C}$, and processed within $48 \mathrm{~h}$. Immunocytochemical stains were conducted with commercially available antibodies: The pan T-lymphocyte marker (polyclonal rabbit antihuman) CD3 (Dako, Glostrup, Denmark) for T-lymphocytes, monoclonal mouse anti-PAX5 antibody (Leica Biosystems, Nussloch, Germany) [43] for B-lymphocytes, and anti-Ki67 monoclonal antibody (MIB-1 mouse) (Dako, Glostrup, Denmark) for proliferation assessment. Immunocytochemical procedures were performed according to the manufacturers' protocols (Novolink Polymer ${ }^{\mathbb{B}}$; Leica Microsystems, Nussloch, Germany), using the indirect immunoperoxidase staining technique. Heat-induced epitope 
retrieval was conducted in a hot water bath $\left(100^{\circ} \mathrm{C}\right.$, $23 \mathrm{~min}$ ) by incubating slides in $10 \mathrm{mM}$ citrated buffer ( $\mathrm{pH}$ 6.0). The slides were then gradually cooled to room temperature. After being washed in $0.05 \mathrm{M}$ tris-buffer ( $\mathrm{pH} 7)$, the slides were incubated with the protein block for $5 \mathrm{~min}$. Each section was then incubated for $120 \mathrm{~min}$ with primary antibodies diluted in $10 \%$ bovine serum albumin (Sigma, Darmstadt, Germany) (CD3 and Ki67 1:50; PAX5 1:40) at room temperature. The endogenous peroxidase activity was neutralized using the peroxidase block, and slides were then incubated with the second antibody (rabbit antimouse $\mathrm{IgG}$ ) for $20 \mathrm{~min}$. Diaminobenzidine was used as a chromogen, and slides were counterstained with Mayer's hematoxylin. Smears of normal spleen were used as positive controls. The percentage of positive cells was determined by counting 300 cells at $\times 400$ magnification in selected fields that showed good cell preservation. All cells with the expected staining pattern (membrane/cytoplasmic for CD3 and nuclear for PAX-5 and Ki67) were considered positive, regardless of the staining intensity. The immunophenotype of each lymphoma was based on the most prevalent number of positive cells [43]. For the proliferation assessment, lymphomas were classified, according to the number of positive Ki67 cells, as follows: Low index $\left(\leq 20 \% \mathrm{Ki}^{+} 7^{+}\right.$cells), moderate index $(20-40 \%$ $\mathrm{Ki} 67^{+}$cells $)$, or high index $\left(>40 \% \mathrm{Ki} 67^{+}\right.$cells $)$as previously described [15].

Tumors were classified according to the updated Kiel classification adapted to the canine species [9], based on cell size and shape; cell volume and intensity of cytoplasm staining; nuclear size, shape, and position; nucleoli size, distinctiveness, number and positioning; appearance of nuclear chromatin; and mitotic indexes (MIs) [44].

\section{Exposure and covariate assessment}

Owners were requested to answer a 70-question questionnaire about their dog's demographics, health-related characteristics, and environmental exposures. Questions regarding the animal included age; sex; breed; reproductive status; date and origin of acquisition (shelter, breeder, pet shop, stray, or other); hair length; nose length; food type; weight; body type; grooming care; use of flea/tick control products; and physical activity levels. Environmental factors included household smoking; house size; use of carpets, rugs, and curtains; house location; the amount of time the dog spent outdoors; the use of fireplace; and exposure to environmental chemicals such as herbicides, pesticides, fungicides, rodenticides, and cleaning products such as bleach and ammonia. When applicable, the questionnaire included exhaustive details about exposure to tobacco smoke and its circumstances, the number of former or current smoking cohabitants, the number of daily consumed cigarettes (or similar), and the length of smoking time during the past decade.

\section{Statistical analysis}

Data were analyzed with the Statistical Package for the Social Sciences (SPSS), version 24. A pairwise comparison with all the collected variables was performed, and the significance of the Spearman's rank correlation coefficient was established. The difference between the average percentage of positive Ki67 cells $\left(\% \mathrm{Ki} 67^{+}\right)$in the groups "smoker owners" and "non-smokers owners" was analyzed with one-way ANOVA. The linear-by-linear association between two levels of smoke exposure and three levels of Ki67 - low, moderate, or high, previously described - was tested with the Chi-squared test. For all tests, a two-sided $p<0.05$ was considered to be statistically significant.

\section{Results \\ Classification}

According to the updated Kiel classification, $65 \%(15 / 23)$ were B-cell and 35\% (8/23) were T-cell lymphomas. Eight morphological subtypes were identified including five B-cell and four T-cell subtypes. Out of the B-cell ones, three were LG centroblastic/ centrocytic (Figure-1) and 12 HGs: One centroblastic large cell, five centroblastic monomorphic, four centroblastic pleomorphic, and two immunoblastic. Out of the eight T-cell lymphomas, two were LG small clear cell, and six were HG: One pleomorphic large cell, one lymphoblastic, and four pleomorphic mixed (Table-1).

\section{Proliferation assessment}

Ki67 ICC was performed in 18 cases with well-preserved cytological smears. The mean $\% \mathrm{Ki} 67^{+}$ was $58.1 \%$ (standard deviation $[\mathrm{SD}]=0.28$ ), and the median was 54\% (range 8-98\%). Thirteen lymphomas were categorized as high proliferation index $(\overline{\mathrm{X}}=0.71$; $\mathrm{SD}=0.19), 11$ of them being $\mathrm{HG}$ ones and two were LG. Two lymphomas presented moderate proliferation

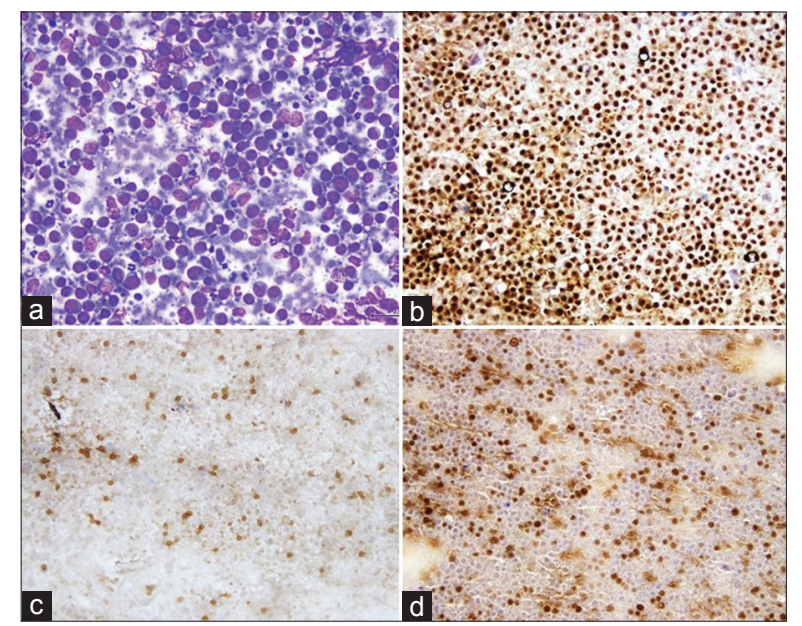

Figure-1: B-cell centroblastic/centrocytic lymphoma of a 3-year-old mongrel female dog. Fine-needle aspiration biopsies of enlarged pre-scapular lymph node. (a) A population of medium-to-large lymphoid cells admixed with very few mature lymphocytes Hemacolor, $\times 400$; (b) PAX5 immunostain $(\times 200)$; (c) CD3 immunostain $(\times 200)$; (d) Ki67 immunostain - moderate index: 40\% $(\times 200)$. 
indexes $(\overline{\mathrm{X}}=0.35 ; \mathrm{SD}=0.06)$, and three cases presented low Ki67 indexes ( $\overline{\mathrm{X}}=0.16$; $\mathrm{SD}=0.69)$ (Table-1).

\section{Epidemiological study}

The series included seven $(30.4 \%)$ mongrel and $16(69.6 \%)$ purebred dogs (six labrador retrievers $-26 \%$, two boxers $-8.7 \%$, and one each of pointer, Portuguese hunting dog, bulldog, cocker spaniel, golden retriever, Castro Laboreiro shepherd, and pit bull terrier). Eleven dogs (47.8\%) were females ( $45 \%$

Table-1: Updated Kiel classification, percentage of Ki67-positive cells and Ki67 indexes, and household smoking status of canine lymphomas.

\begin{tabular}{|c|c|c|c|c|}
\hline $\begin{array}{l}\text { Kiel } \\
\text { classification }\end{array}$ & \%Ki67+ & $\begin{array}{l}\text { Ki67 } \\
\text { Index }\end{array}$ & $\begin{array}{l}\text { Smoker } \\
\text { owners }\end{array}$ & $\begin{array}{c}\text { Number } \\
\text { of } \\
\text { smokers }\end{array}$ \\
\hline \multicolumn{5}{|l|}{$\begin{array}{l}\text { B-cell lymphomas } \\
\text { High grade }\end{array}$} \\
\hline $\begin{array}{l}\text { Centroblastic } \\
\text { large cell }\end{array}$ & 48 & High & Yes & 2 \\
\hline $\begin{array}{l}\text { Centroblastic } \\
\text { monomorphic }\end{array}$ & 88 & High & Yes & 1 \\
\hline $\begin{array}{l}\text { Centroblastic } \\
\text { monomorphic }\end{array}$ & 52 & High & Yes & 2 \\
\hline $\begin{array}{l}\text { Centroblastic } \\
\text { monomorphic }\end{array}$ & 51 & High & - & - \\
\hline $\begin{array}{l}\text { Centroblastic } \\
\text { monomorphic }\end{array}$ & - & - & Yes & 1 \\
\hline $\begin{array}{l}\text { Centroblastic } \\
\text { monomorphic }\end{array}$ & - & - & No & 0 \\
\hline $\begin{array}{l}\text { Centroblastic } \\
\text { pleomorphic }\end{array}$ & 31 & Moderate & Yes & 1 \\
\hline $\begin{array}{l}\text { Centroblastic } \\
\text { pleomorphic }\end{array}$ & 89 & High & - & - \\
\hline $\begin{array}{l}\text { Centroblastic } \\
\text { pleomorphic }\end{array}$ & 95 & High & - & - \\
\hline $\begin{array}{l}\text { Centroblastic } \\
\text { pleomorphic }\end{array}$ & - & - & Yes & 2 \\
\hline Immunoblastic & 83 & High & Yes & 1 \\
\hline Immunoblastic & 90 & High & Yes & 1 \\
\hline $\begin{array}{l}\text { Low-grade } \\
\text { Centroblastic/ }\end{array}$ & 42 & High & Yes & 1 \\
\hline $\begin{array}{l}\text { Centroblastic/ } \\
\text { centrocytic }\end{array}$ & 20 & Low & No & 0 \\
\hline $\begin{array}{l}\text { Centroblastic/ } \\
\text { centrocytic }\end{array}$ & 40 & Moderate & No & 0 \\
\hline \multicolumn{5}{|l|}{ T-cell Iymphomas } \\
\hline Lymphoblastic & 8 & Low & No & 0 \\
\hline $\begin{array}{l}\text { Pleomorphic } \\
\text { mixed }\end{array}$ & 87 & High & Yes & 2 \\
\hline $\begin{array}{l}\text { Pleomorphic } \\
\text { mixed }\end{array}$ & 61 & High & Yes & 1 \\
\hline $\begin{array}{l}\text { Pleomorphic } \\
\text { mixed }\end{array}$ & 56 & High & No & 0 \\
\hline $\begin{array}{l}\text { Pleomorphic } \\
\text { mixed }\end{array}$ & - & - & No & 0 \\
\hline $\begin{array}{l}\text { Pleomorphic } \\
\text { large cells } \\
\text { Low-grade }\end{array}$ & - & - & No & 0 \\
\hline $\begin{array}{l}\text { Small clear } \\
\text { cell type }\end{array}$ & 85 & High & - & - \\
\hline $\begin{array}{l}\text { Small clear } \\
\text { cell type }\end{array}$ & 20 & Low & No & 0 \\
\hline
\end{tabular}

spayed), and $12(52.2 \%)$ were males ( $8 \%$ castrated). The mean age was 8.1 years (range, $3-15$ years).

The epidemiologic questionnaire was completed by all dog owners although only 19 answered the section concerning smoking habits (Table-1). The results showed that in 11 out of 19 cases $(57.89 \%)$ either the owners or other cohabitants, from 2005 to 2016, were or had been active smokers. In seven cases $(63.7 \%)$, the dog lived with one smoker, while in the remaining cases $(36.3 \%)$, there were two smokers cohabiting with the dog.

Pairwise comparison between all studied variables revealed a statistically significant positive correlation $(\mathrm{r}=0.753, \mathrm{p}=0.002)$ and significant linear-by-linear association $(\mathrm{p}=0.018)$ between the Ki67 index and smoking status. Data also revealed a statistically significant positive correlation between the Ki67 index and the number of smokers who lived with the $\operatorname{dog}(\mathrm{r}=0.641, \mathrm{p}=0.018)$. The ANOVA test confirmed a significantly different $(\mathrm{p}=0.011)$ mean percentage of $\mathrm{Ki} 67^{+}$cells between the groups "non-smoker owners" $(\mathrm{X}=0.25 ; \mathrm{SD}=0.19)$ and "smoker owners" $(\mathrm{X}=0.64$; $\mathrm{SD}=0.22$ ) (Figure-2). Neither other environmental factors nor geographical localization revealed significant relations with subtype, grade, or tumor proliferation index.

\section{Discussion}

Since lymphomas are a wide group of hematopoietic neoplasms with a broad range of potential outcomes $[2,7,16]$, the simple diagnosis of "lymphoma" is of limited value for the clinical management of patients or even for the conduction of epidemiological studies. ICC plays a unique role in the improvement of the cytological diagnosis of canine lymphoma.

As lymphoid tissues lack in cellular cohesion, they permit a rich cellular harvest, so well-executed cytological collection procedures followed by adequate processing allow for obtaining useful

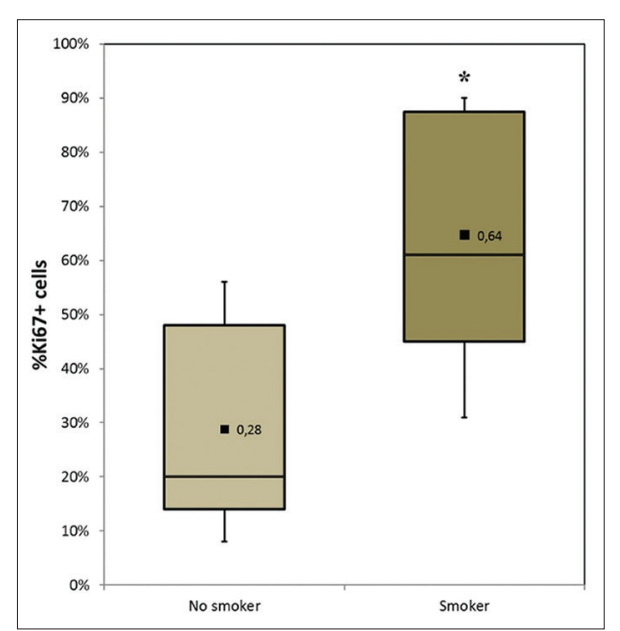

Figure-2: Box-and-whisker diagram depicting the percentage of $\mathrm{Ki} 67^{+}$cells categorized by the smoking status. Represents the mean percentage of $\mathrm{Ki} 67^{+}$cells per group. Lymphomas affecting dogs owned by smokers have a significantly higher mean percentage of $\mathrm{Ki} 67^{+}$cells $(p<0.05)$. 
diagnostic information [45]. In our study, FNB was performed without suction (the Zajdela or "French" technique) $[8,46]$. Although this technique potentially reduces the amount of harvested material, the preparations are more representative, less contaminated with blood and other cells [8] and cells are better preserved, which indeed contributes for the quality of immunocytochemical analysis.

Lymphoma cytological subtyping is challenging, and the use of ICC plays a vital role in both the diagnosis and subtyping [8]. Although all lymphoma immunophenotyping techniques - immunohistochemistry, flow cytometry, and PARR - have their particular advantages [8], ICC allows for morphological evaluation of stained cells as well as staining location and intensity in a simple smear, thus reducing costs and procedures.

MI and Ki67 immunolabeling are the proliferation parameters more commonly used in veterinary oncology [7]. Counting the number of mitotic figures in cytological preparations can be misleading and lacks representativeness, mainly due to an irregular cell distribution [7]. The ICC for Ki67, a non-histone nuclear protein expressed in all stages of the cell cycle, may overcome this difficulty and thus improve the assessment of the proliferation activity of lymphomas. It has been shown that the Ki67 immunolabeling of cytological smears had high concordance with Ki67 immunohistochemistry in biopsy tissues [9]. In this study, we opted to count 300 cells per tumor, a higher number than previously reported (100 cells), to ensure the reliability of the results $[7,47]$.

In our series, there was a higher prevalence of B-cell (65\%) over T-cell lymphomas (35\%), and $56.5 \%$ were $\mathrm{HG}$ tumors (13/23). Interestingly, Ki67 index differences were detected within tumors of similar grades, both in B- and T-cell lymphomas. There was no statistically significant correlation between Kiel's grades and Ki67 indexes or the percentage of Ki67-positive cells. Considering that cytotoxic chemotherapy is the preferred treatment for dogs with lymphoma and that it is known that it yields better responses in highly proliferating tumors, it is possible that subtyping and grading fail as prognostic and predictive indicators if not complemented with proliferation markers. In human mantle-cell lymphoma, the Ki-67 index has already surpassed cytology and growth pattern as prognostic factors [48]. Moreover, survival time discrepancies within canine lymphoma subtypes have already been demonstrated by Ponce et al. [12]. In a recent study [15] of HG B-cell lymphomas treated with a modified Wisconsin-Madison protocol, dogs affected by tumors of intermediate Ki67\% indexes presented longer survival and relapsefree intervals than those with low or high $\mathrm{Ki} 67 \%$, as determined by flow cytometry. In human medicine, Hall et al. [49] analyzed the survival rate of patients with different grades and Ki67 indexes, demonstrating that those affected by LG NHL with high Ki67 indexes had worse survival rates than those with low Ki67 index and that HG NHL with very high Ki67 indexes had better survival rates when compared to those with lower indexes. Therefore, Hoster et al. recommended that Ki67 index should be routinely estimated in clinical practice to allow for more accurate individual risk estimation [48].

Some of the described discrepancies between subtypes and proliferation indexes, particularly in the LG T-cell small clear subtype with high Ki67 index, may be related to the process of transformation. As defined by the European canine lymphoma group, "transformation is the evolution of an indolent to an aggressive lymphoma, typically harboring a very poor prognosis" [3]. In veterinary medicine, this phenomenon has been undervalued, although it is a possible indolent lymphomas' evolution [50]. To the best of authors' knowledge, however, there were no reports confirming the transformation of canine indolent lymphomas.

Different factors such as genetic modifications, epigenetic transformations, and microenvironmental conditions may contribute to reprograming and transforming the original neoplastic mass into a more aggressive one [50,51]. Furthermore, lifestyle factors such as smoking habits, obesity, and alcohol consumption have been shown to influence the overall survival rate of human NHL patients [52].

The potential links between environmental pollutants and the risk of developing human NHL [24,31] and canine lymphomas [6,20,21,53] have been described. There is, however, a lack of studies relating environmental factors to the biological behavior of canine lymphomas, particularly those with potential prognostic or predictive value.

In our series, albeit small, a statistically significant relationship between exposure to tobacco smoke and the lymphomas' proliferation, as expressed by the Ki67 index, emerged. High Ki67 indexes were positively correlated with the number of smoker cohabitants. These results are consistent with the hypothesis that second- and third-hand exposure to tobacco smoke could be considered as a hazardous factor for dogs with lymphomas by being associated with enhancement of their proliferative activity or transformation. Yet, it should be noted and highlighted that larger and more controlled studies are warranted to confirm this hypothesis. Given the small sample used, the external validity of this study is not possible.

\section{Conclusion}

In summary, our results suggest that the cytological diagnosis of canine lymphomas benefits from being complemented with immunocytochemical studies that include subtyping and proliferative assessment, both contributing for the prognosis and the therapeutic planning. Furthermore, exposure to tobacco smoke in second- and third-hand ways seems to be 
related to higher proliferating indexes of canine lymphomas, independently of their subtype or grade.

\section{Authors' Contributions}

$\mathrm{KCP}$ was the research executer and coordinator. MS collaborated in the cytological diagnosis and LLM with sample collection. JNR oriented and supervised data analysis. AJM participated in the study planning, execution, and manuscript revising. All authors read and approved the final manuscript.

\section{Acknowledgments}

The authors would like to thank Hugo Gregório of the Centro Hospitalar Veterinário (CHV); Gonçalo Petrucci of the Hospital Veterinário do Porto (HVP); Filipe Oliveira of the Hospital Veterinário de Referência Montenegro (HVRM); and Hugo Carvalho and Nazaré Pinto da Cunha of the veterinary laboratory CEDIVET, for their contribution to this study. Moreover, we would like to express our deep gratitude to Professor Dr. Fátima Gartner of the Department of Pathology and Immunology of ICBAS - University of Porto, for enabling the study.

This research was supported by an international $\mathrm{PhD}$ fellowship from CAPES (Coordenação de Aperfeiçoamento de Pessoal de Nível Superior), Brazil (CSF 0342-13-0).

\section{Competing Interests} interests.

The authors declare that they have no competing

\section{References}

1. Bassig, B.A., Lan, Q., Rothman, N., Zhang, Y. and Zheng, T. (2012) Current understanding of lifestyle and environmental factors and risk of non-Hodgkin lymphoma: An epidemiological update. J. Cancer Epidemiol., 2012: 978930.

2. Vail, D.M., Pinkerton, M.E. and Young, K.M. (2012) Canine lymphoma and lymphoid leukemia. In: Elseviers, S., editor. Withrow and MacEwen's Small Animal Clinical Oncology. $5^{\text {th }}$ ed. Elsevier, St. Louis. p608-638.

3. Comazzi, S., Guscetti, F. and Marconato, L. (2014) First meeting of the European canine lymphoma group. Workshop: State of the art and comparative aspects in canine lymphoma, CH-lugano, 22 June 2013. Hematol. Oncol., 32: 68-71.

4. Siegel, R.L., Miller, K.D. and Jemal, A. (2016) Cancer statistics, 2016. CA Cancer J. Clin., 66: 7-30.

5. Ponce, F., Marchal, T., Magnol, J.P., Turinelli, V., Ledieu, D., Bonnefont, C., Pastor, M., Delignette, M.L. and FournelFleury, C. (2010) A morphological study of 608 cases of canine malignant lymphoma in France with a focus on comparative similarities between canine and human lymphoma morphology. Vet. Pathol., 47: 414-433.

6. Takashima-Uebelhoer, B.B., Barber, L.G., Zagarins, S.E., Procter-Gray, E., Gollenberg, A.L., Moore, A.S. and Bertone-Johnson, E.R. (2012) Household chemical exposures and the risk of canine malignant lymphoma, a model for human non-Hodgkin's lymphoma. Environ. Res., 112: 171-176.

7. Sapierzynski, R., Kliczkowska-Klarowicz, K., Jankowska, U. and Jagielski, D. (2016) Cytodiagnostics of canine lymphomas-possibilities and limitations. Pol. J. Vet. Sci., 19: 433-439.

8. Wieczorek, T.J., Paul, E. and Wakely, J. (2014) Lymph nodes. In: Elseviers, S., editor. Cytology-Diagnostic Principles and Clinical Correlates. $4^{\text {th }}$ ed. Elsevier, Churchill Livingstone.

9. Fournel-Fleury, C., Magnol, J.P., Chabanne, L., Ghernati, I., Marchal, T., Bonnefont, C., Bryon, A. and Felman, P. (1997) Growth fractions in canine non-Hodgkin's lymphomas as determined in situ by yhe expression of the Ki-67 antigen. J. Comp. Pathol., 117: 61-72.

10. Sapierzyński, R., Dolka, I. and Fabisiak, M. (2012) High agreement of routine cytopathology and immunocytochemistry in canine lymphomas. Pol. J. Vet. Sci., 15: 247-252.

11. Fournel-Fleury, C., Magnol, J.P., Bricaire, P., Marchal, T., Chabanne, L., Delverdier, A., Bryon, P.A. and Felman, P. (1997) Cytohistological and immunological classification of canine malignant lymphomas: Comparison with human non-Hodgkin's lymphomas. J. Comp. Pathol., 117: 35-59.

12. Ponce, F., Magnol, J.P., Ledieu, D., Marchal, T., Turinelli, V., Chalvet-Monfray, K. and Fournel-Fleury, C. (2004) Prognostic significance of morphological subtypes in canine malignant lymphomas during chemotherapy. Vet. J., 167: 158-166.

13. Fournel-Fleury, C., Ponce, F., Felman, P., Blavier, A., Bonnefont, C., Chabanne, L., Marchal, T., Cadore, J.L., Goy-Thollot, I., Ledieu, D., Ghernati, I. and Magnol, J.P. (2002) Canine T-cell lymphomas: A morphological, immunological, and clinical study of 46 new cases. Vet. Pathol., 39: 92-109.

14. Lennert, K. (1992) Non-Hodgkin's lymphomas: Principles and application of the Kiel classification. Verh. Dtsch. Ges. Pathol., 76: 1-13.

15. Poggi, A., Miniscalco, B., Morello, E., Gattino, F., Delaude, A., Ferrero Poschetto, L., Aresu, L., Gelain, M.E., Martini, V., Comazzi, S. and Riondato, F. (2016) Prognostic significance of Ki67 evaluated by flow cytometry in dogs with high-grade B-cell lymphoma. Vet. Comp. Oncol., 15(2): 431-440.

16. Kiupel, M., Teske, E. and Bostock, D. (1999) Prognostic factors for treated canine malignant lymphoma. Vet. Pathol., 36: 292-300.

17. Valli, V.E., Kass, P.H., San Myint, M. and Scott, F. (2013) Canine lymphomas: Association of classification type, disease stage, tumor subtype, mitotic rate, and treatment with survival. Vet. Pathol., 50: 738-748.

18. Sokolowska, J., Micun, J., Malicka, E. and Lechowski, R. (2012) Proliferation activity in canine lymphomas. Pol. J. Vet. Sci., 15: 717-734.

19. Backer, L.C., Grindem, C.B., Corbett, W.T., Cullins, L. and Hunter, J.L. (2001) Pet dogs as sentinels for environmental contamination. Sci. Total Environ., 274: 161-169.

20. Gavazza, A., Presciuttini, S., Barale, R., Lubas, G. and Gugliucci, B. (2001) Association between canine malignant lymphoma, living in industrial areas, and use of chemicals by dog owners. J. Vet. Intern. Med., 15: 190-195.

21. Zanini, D., Kimura, K., Nishiya, A., Ubukata, R., Leandro, R., Brito, C., Trombetti, M., Lagoa, A., Macedo, T., Rodrigues, L., Rosendo, J., Arndt, H., Dias, R. and Dagli, M. (2013) Environmental risk factors related to the development of canine non-Hodgkin's lymphoma. Ciênc. Rural, 43: 1302-1308.

22. Ito, D., Frantz, A.M. and Modiano, J.F. (2014) Canine lymphoma as a comparative model for human non-Hodgkin lymphoma: Recent progress and applications. Vet. Immunol. Immunopathol., 159: 192-201.

23. Marconato, L., Gelain, M.E. and Comazzi, S. (2013) The dog as a possible animal model for human non-Hodgkin lymphoma: A review. Hematol. Oncol., 31: 1-9.

24. Czarnota, J., Gennings, C., Colt, J.S., de Roos, A.J., Cerhan, J.R., Severson, R.K., Hartge, P., Ward, M.H. and Wheeler, D.C. (2015) Analysis of environmental chemical mixtures and non-hodgkin lymphoma risk in the NCI-SEER NHL study. Environ. Health Perspect., 123: 965-970.

25. Chihara, D., Nastoupil, L.J., Williams, J.N., Lee, P., 
Koff, J.L. and Flowers, C.R. (2015) New insights into the epidemiology of non-Hodgkin lymphoma and implications for therapy. Expert Rev. Anticancer Ther., 15: 531-544.

26. Lu, Y., Wang, S.S., Reynolds, P., Chang, E.T., Ma, H., Sullivan-Halley, J., Clarke, C.A. and Bernstein, L. (2011) Cigarette smoking, passive smoking, and non-Hodgkin lymphoma risk: Evidence from the California teachers study. Am. J. Epidemiol., 174: 563-573.

27. Dobson, J.M. (2013) Breed-predispositions to cancer in pedigree dogs. ISRN Vet. Sci., 2013: 941275.

28. Villamil, J.A., Henry, C.J., Hahn, A.W., Bryan, J.N., Tyler, J.W. and Caldwell, C.W. (2009) Hormonal and sex impact on the epidemiology of canine lymphoma. J. Cancer Epidemiol., 2009: 591753.

29. Duncan, A.W., Marr, H.S., Birkenheuer, A.J., Maggi, R.G., Williams, L.E., Correa, M.T. and Breitschwerdt, E.B. (2008) Bartonella DNA in the blood and lymph nodes of golden retrievers with lymphoma and in healthy controls. J. Vet. Intern. Med., 22: 89-95.

30. Pasquini, A., Gavazza, A. and Biagi, G. (2013) Oxidative stress in lymphoma: Similarities and differences between dog and human. Comp. Clin. Pathol., 24: 69-73.

31. DellaValle, C.T., Deziel, N.C., Jones, R.R., Colt, J.S., De Roos, A.J., Cerhan, J.R., Cozen, W., Severson, R.K., Flory, A.R., Morton, L.M. and Ward, M.H. (2016) Polycyclic aromatic hydrocarbons: Determinants of residential carpet dust levels and risk of non-Hodgkin lymphoma. Cancer Causes Control, 27: 1-13.

32. Hayes, H.M., Tarone, R.E., Cantor, K.P., Jessen, C.R., McCurnin, D.M. and Richardson, R.C. (1991) Case-control study of canine malignant lymphoma: Positive association with dog owner's use of 2,4-dichlorophenoxyacetic acid herbicides. J. Natl. Cancer Inst., 83: 1226-1231.

33. Reif, J.S., Lower, K.S. and Ogilvie, G.K. (1995) Residential exposure to magnetic fields and risk of canine lymphoma. Am. J. Epidemiol., 141: 352-359.

34. Marconato, L., Leo, C., Girelli, R., Salvi, S., Abramo, F., Bettini, G., Comazzi, S., Nardi, P., Albanese, F. and Zini, E. (2009) Association between waste management and cancer in companion animals. J. Vet. Intern. Med., 23: 564-569.

35. IARC-Working-Group-on-the-Evaluation-ofCarcinogenic-Risks-to-Humans. (2012) Personal habits and indoor combustions. Volume 100E. A review of human carcinogens. IARC Monogr. Eval. Carcinog. Risks Hum., 100: $1-538$.

36. IARC-Working-Group-on-the-Evaluation-ofCarcinogenic-Risks-to-Humans. (2004) Tobacco smoke and involuntary smoking. IARC Monogr. Eval. Carcinog. Risks Hum., 83: 1-1438.

37. Ganjre, A.P. and Sarode, G.S. (2016) Third hand smoke--a hidden demon. Oral Oncol., 54: e3-e4.

38. Diver, W.R., Teras, L.R., Gaudet, M.M. and Gapstur, S.M. (2014) Exposure to environmental tobacco smoke and risk of non-Hodgkin lymphoma in nonsmoking men and women. Am. J. Epidemiol., 179: 987-995.

39. Roza, M.R. and Viegas, C.A. (2007) The dog as a passive smoker: Effects of exposure to environmental cigarette smoke on domestic dogs. Nicotine Tob. Res., 9: 1171-1176.

40. Carter, R.F. and Valli, V.E. (1988) Advances in the cytologic diagnosis of canine lymphoma. Semin. Vet. Med. Surg. Small Anim., 3: 167-175.

41. Caniatti, M., Roccabianca, P., Scanziani, E., Paltrinieri, S. and Moore, P.F. (1996) Canine lymphoma: Immunocytochemical analysis of fine-needle aspiration biopsy. Vet. Pathol., 33: 204-212.

42. Messick, J. (2008) The lymph nodes. In: Cowell, R., Tyler, R., Meinkoth, J. and de Nicola, B., editors. Diagnostic Cytology and Hematology of the Dog and Cat. Mosby Elsevier, St. Louis, MO. p179-191.

43. Willmann, M., Mullauer, L., Guija de Arespacochaga, A., Reifinger, M., Mosberger, I. and Thalhammer, J.G. (2009) Pax5 immunostaining in paraffin-embedded sections of canine non-Hodgkin lymphoma: A novel canine pan preB- and B-cell marker. Vet. Immunol. Immunopathol., 128: 359-365.

44. Jankowska, U., Jagielski, D., Czopowicz, M. and Sapierzynski, R. (2015) The animal-dependent risk factors in canine T-cell lymphomas. Vet. Comp. Oncol., 15: 307-314.

45. Schwock, J. and Geddie, W.R. (2012) Diagnosis of B-cell non-hodgkin lymphomas with small-/intermediate-sized cells in cytopathology. Patholog. Res. Int., 2012: 164934.

46. Zajdela, A., Zillhardt, P. and Voillemot, N. (1987) Cytological diagnosis by fine needle sampling without aspiration. Cancer, 59: 1201-1205.

47. Bauer, N.B., Zervos, D. and Moritz, A. (2007) Argyrophilic nucleolar organizing regions and Ki67 equally reflect proliferation in fine needle aspirates of normal, hyperplastic, inflamed, and neoplastic canine lymph nodes $(\mathrm{n}=101)$. J. Vet. Intern. Med., 21: 928-935.

48. Hoster, E., Rosenwald, A., Berger, F., Bernd, H.W., Hartmann, S., Loddenkemper, C. and Agnelli, E. (2016) Prognostic value of Ki-67 index, cytology, and growth pattern in mantle-cell lymphoma: Results from randomized trials of the European mantle cell lymphoma network. J. Clin. Oncol., 34: 1386-1394.

49. Hall, P.A., Richards, M.A., Gregory, W.M., d'Ardenne, A.J., Lister, T.A. and Stansfeld, A.G. (1988) The prognostic value of Ki67 immunostaining in non-Hodgkin's lymphoma. J. Pathol., 154: 223-235.

50. Comazzi, S., Aresu, L. and Marconato, L. (2015) Transformation of canine lymphoma/leukemia to more aggressive diseases: Anecdotes or reality? Front. Vet. Sci., 2: 42 .

51. Casulo, C. and Friedberg, J. (2017) Transformation of marginal zone lymphoma (and association with other lymphomas). Best Pract. Res. Clin. Haematol., 30: 131-138.

52. Geyer, S.M., Morton, L.M., Habermann, T.M., Allmer, C., Davis, S., Cozen, W., Severson, R.K., Lynch, C.F., Wang, S.S., Maurer, M.J., Hartge, P. and Cerhan, J.R. (2010) Smoking, alcohol use, obesity, and overall survival from non-Hodgkin lymphoma: A population-based study. Cancer, 116: 2993-3000.

53. Bertone, E.R., Snyder, L.A. and Moore, A.S. (2002) Environmental tobacco smoke and risk of malignant lymphoma in pet cats. Am. J. Epidemiol., 156: 268-273. 